\title{
Comments on Thomas Kuhn's Philosophy of Language
}

\author{
Mauro L. Condé 1
}

Reference of the commented article: PIROZELLI, Paulo. Thomas Kuhn's Philosophy of Language. Trans/Form/Ação: revista de filosofia da Unesp, vol. 43, Número Especial, p. 345-372, 2020.

Paulo Pirozelli's article "Thomas Kuhn's philosophy of language" makes a significant contribution to the understanding of the philosophy of language that is present in the last period of Kuhn's work and, indirectly, to the understanding that most of the problems in the philosophy of science and epistemology which are inevitably linguistic problems. Pirozelli demonstrates that when Kuhn encountered serious problems in his book, The Structure of Scientific Revolutions - especially concerning the concepts of "scientific revolution" and "incommensurability" -, he realized that the solution to such problems would be in language and, thus, gradually established a linguistic reflection to solve them. Kuhn is a renowned author of history and philosophy of science, but in his later works, he devoted himself intensely to issues of language. ${ }^{2}$

In what follows, I will make two related comments (or two aspects on the same point) in Pirozelli's article, which are (1) the relationship between Kuhn and Wittgenstein and (2) how the Wittgensteinian work may still help us to solve the problem of the kind terms presented by Kuhn, especially as to

\footnotetext{
${ }^{1}$ Full Professor of History of Science [Historiography of Science] at the Federal University of Minas Gerais (UFMG), Belo Horizonte, MG - Brazil. (D) https://www.orcid.org/0000-0003-4156-2926 E-mails: mauroconde@ufmg.br - maurollconde@gmail.com

2 Towards the end of his life, in 1995, Kuhn stated: "much of my thoughts these days goes to language" (KUHN 2000, 259).
}

http://doi.org/10.1590/0101-3173.2020.v43esp.26.p373

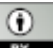

This is an open-access article distributed under the terms of the Creative Commons Attribution License. 
how one can better understand the kind terms Kuhn calls nomic, or the kind terms which we learn with the laws of nature.

Although the focus of Pirozelli's article is not precisely about Kuhn's philosophy of science, the strong connection between language and science makes us understand the philosophy of language present in Kuhn's last writings not necessarily as a "theory of language" that has a purpose in and of itself, but rather as something at the service of a "theory of science" (philosophy of science) and its historical understanding (history of science). To a certain extent, although the author of The Road since Structure delves into linguistic issues, he is not precisely a philosopher of language, but a thinker who imports linguistic reflections and shapes them in his manner to think about the history and philosophy of science.

The basis of this Kuhnian enterprise is undeniably linked to the later Wittgenstein's philosophy of language. Not only is the Kuhnian concept of lexicon very similar to the Wittgensteinian notion of grammar (WITTGENSTEIN, $2009 \$ 520$, 664), but there are also several concepts forged by the Austrian philosopher such as "language-games", "use", "family resemblance" and "form of life" recurrent in the Kuhnian texts (KUHN, 2000, p. 62, 63, 100, 244, 245). ${ }^{3}$ Certainly, by having the philosophy of science as a central concern, Kuhn gives a peculiar use to the appropriations he makes of Wittgenstein's philosophy of language. At some points, he follows Wittgenstein, and at other times he goes beyond him, but later, he directly opposes the Austrian philosopher.

Perhaps, the main opposition between Kuhn's philosophy of language and Wittgenstein's philosophy - which creates difficulties in the progress of the former's ideas on language and science - lies in the Kantian affiliation assumed by Kuhn in his later philosophical thoughts. To understand the scientist's production of knowledge in his interactions with nature, Kuhn creates his concept of lexicon, however, to support such a concept he uses the author of The Critique of Pure Reason to rehabilitate some metaphysical ideas such as "categories", "synthetic", "a priori". This is an aspect that distances Kuhn considerably from Wittgenstein since the author of the Philosophical Investigations sought precisely to construct a new philosophy that would free

${ }^{3}$ Kuhn recognizes Wittgenstein's "recurrent role" in his "philosophical development" (Kuhn, 2000, p. 72). Numerous passages in Pirozelli's article, by reconstructing Kuhn's philosophy of language, show this Wittgensteinian atmosphere. In some passages of his article, the reference is direct, in addition to Wittgenstein being the only philosopher of language to be directly quoted by Pirozelli. 
us from these metaphysical bonds - such as those established by Kant and other traditional philosophers - which "bewitch" us and prevent us from having a more adequate understanding of philosophical issues.

To keep some distance from the metaphysical perspective present in Kant as well as all traditional philosophy, according to Wittgenstein, it is necessary to adopt the pragmatic viewpoint of language-games and its grammar, furthermore, overcoming what a merely semantic (and essentialist) viewpoint has been imposed by this traditional philosophy (which was defended by Wittgenstein himself when he wrote his Tractatus Logico-Philosophicus). Kuhn assimilated numerous Wittgensteinian conceptions, however, he turned away from an entirely pragmatic viewpoint by approaching, at least, this Kantian metaphysical vocabulary. To make the connection between different lexicons, Kuhn concludes that his theory presupposes the Kantian notions of categories and Ding an sich. "The position I'm developing is a sort of Post-Darwinian Kantianism. Like the Kantian categories, the lexicon supplies preconditions of possible experience" (KUHN, 2000, p. 104). The Kuhnian lexicon would, therefore, give the "conditions of possibility" to acquire knowledge about natural phenomena. This would make the knowledge of the world to some extent dependent on human perception, but, as with Kant, not completely (since it would rest on the ineffable). To be precise, Kuhn further emphasizes his Kantian position by postulating that what guarantees the possibility of change among lexicons is some kind of Ding an sich. Kuhn states: "Underlying all these processes of differentiation and change, there must, of course, be something permanent, fixed and stable. But, like Kant's Ding an sich, it is ineffable, undescribable, undiscussible" (KUHN 2000, p. 104).

However, as Pirozelli observed, Kuhn attempts to mitigate the metaphysical nature of the Kantian concepts of categories and Ding an sich by giving them historical and social aspects, "but lexical categories, unlike their Kantian forebears, can and do change, both with time and with the passage from one community to another" (KUHN, 2000, p. 104). Nevertheless, this Kantian position ultimately limits Kuhn's epistemology, since he does not ground it directly in the nature, social and technological contexts of knowledge production, but rather links it to the Kantian metaphysics of the ineffable. In other words, Kuhn advances to understand language as an essential aspect in the production of scientific knowledge, yet fails to give his theory of lexicon a sufficiently pragmatic stance and ultimately resorts to a metaphysics of the ineffable, indescribable, and indisputable to justify it. 
One can see a strong difference between the Wittgensteinian notion of grammar and the Kuhnian lexicon. The notion of grammar promotes the understanding of language from a different perspective than the traditional semantic conception of language based on the idea of representation of nature by means of categories, conceptual schemes, etc. From the pragmatical viewpoint of grammar, there is a social (collective) interaction of mankind with nature and not a representation based on these categories or conceptual schemes. Although Kuhn agrees with some pragmatical aspects of Wittgenstein's philosophy, against the Kuhnian viewpoint, the ultimate Wittgensteinian position breaks away from the Aristotelian and Kantian grammar of categorization, thereby establishing a new "grammatical consideration" (WITTGENSTEIN, $2009 \$ 90$ ), or a new pragmatical point of view to solve old philosophical problems emerging in the assumption of categories and representation. The main target is no longer about building categories, as Kuhn wanted by rehabilitating Kant's ideas, but about "following the rules of the language game" (WITTGENSTEIN, $2008 \$ 206$ ) in the grammar of a form of life (or the scientific community in terms of the Kuhnian vocabulary). In conclusion, following the rules allows us to understand the grammar that connects us to the social and natural world.

From this Wittgensteinian position, we can shed some light on one of the central points mentioned by Pirozelli, namely his analysis of the differentiation of the Kuhnian concepts of nomic and normic. As highlighted in "Thomas Kuhn's philosophy of language", Kuhn himself did not deal with this point at length. We could then try to advance our understanding from the contribution of Wittgensteinian grammar.

According to Pirozelli, in opposition to normic terms, Kuhn calls nomic terms like "force" or "electric charge". These kind terms are "learned from situations in which they occur together, situations exemplifying laws of nature" (KUHN, 993a, p. 231; 1983, p. 211) (PIROZELLI, p. 363), that is, the connection between theories and laws of nature play a very important "role in establishing the reference of these terms" (KUHN, 1979, p. 200) (PIROZELLI, p. 363). Considering the specific aspect of the nomic terms by connecting theory and laws of nature, perhaps, we might find in Wittgensteinian grammar a good key to interpret them.

According to the author of Philosophical Investigations, some languagegames are results of social interactions, but others come from our relationship to nature. Therefore, Wittgensteinian grammar can also consider two types 
of kind terms or two types of language-games. Those that predominantly involve social aspects, and those that predominantly involve natural aspects. In other words, in Wittgenstein, we would have not only kind terms like normic, considering that grammar constitutes its rules in our "behavior patterns", our habits, customs, and institutions (WITTGENSTEIN, 2009, $\$ \$ 142,199,202,226,227)$, but also kind terms like nomic, in which one learns simultaneously with laws of nature, considering that grammar connects with nature. For Wittgenstein, if the facts behaved differently, our languagegames would be different. In other words, although our grammar is not reduced to facts, if these facts were different, our language games would also be different, consequently our grammar would be different. "If we imagine the facts otherwise than as they are, certain language-games lose some of their importance, while others become important" (WITTGENSTEIN, 1979, $\$$ 63). This point shows the important interconnection between grammar and nature. Even though the law is "built into the lexicon" (KUHN, 1989, p. 71), as observed by Pirozelli, of course, the law depends on nature.

In this way, Wittgenstein's grammar follows some of the assumptions of Kuhn's theory, namely,

[(1)] a law of nature is not analytic: its necessity does not derive from the definition of independent terms, but is intertwined with some concepts that are defined concomitantly with it through stipulative generalizations (KUHN, 1989, p. 73, n. 19) [(2)] terms for species are family resemblance concepts, which requires that they must be learned simultaneously, within a set of contrasting concepts. These networks of related concepts are called 'taxonomies' or 'lexicons' [or grammar in Wittgensteinian terms] (PIROZELLI, 2020, p. 366).

However, the grammar is against the Kuhnian taxonomy when Kuhn

[...] sees that these natural laws are closer to the Kantian idea of synthetic $a$ priori: 'synthetic', because they cannot 'exist in the absence of experience'; and a priori, because 'their experiential and their definitional content are inseparably merged' (KUHN, 1999, p. 36) (PIROZELLI, 2020, p. 366).

In a Wittgensteinian viewpoint, the nomic terms could not be established as a synthetic a priori by means of categories or "conceptual scheme" but just in the understanding of the language-games in a form of life that involves the social and the natural. 
Of course, a complete demonstration of this point needs more space than is allocated to in these short comments. However, I hope the reader would be curious enough to investigate this further in order to see for her or himself that Kuhn's philosophy of science and Wittgenstein's philosophy of language have a lot of fruitful family resemblances and can help us solve our linguistic and epistemological problems. So, I hope this excellent article of Pirozelli will inspire us all to explore the relationship between the works of Kuhn and Wittgenstein.

\section{REFERENCES}

KUHN, Thomas. The Road since Structure. Chicago: Chicago University Press, 2000. WITTGENSTEIN, Ludwig. Philosophical Investigations. Basil: Wiley-Blackwell, 2009.

WITTGENSTEIN, Ludwig. On Certainty, ed. G.E.M. Anscombe and G. H. Von

Wright, trans. Denis Paul and G. E. M. Anscombe Oxford: Basil Blackwell, 1979.

Recebido: 05/06/2020

Aceito: 27/06/2020 